\title{
ANALYSIS OF THE HLA-DRw9 ANTIGEN USING TWO-DIMENSIONAL GEL ELECTROPHORESIS AND ALLOANTISERA
}

\author{
Toshio Yabe, ${ }^{1}$ Manabu Suzuki, ${ }^{1}$ Ryozaburo MukaI, ${ }^{1}$ \\ Masahiro Satake, ${ }^{2}$ Takeo JuJi, ${ }^{2}$ and Hideo HamaguChi ${ }^{1, *}$ \\ ${ }^{1}$ Department of Human Genetics, Institute of Basic Medical Sciences, \\ University of Tsukuba, Niihari-gun, Ibaraki 305, Japan \\ ${ }^{2}$ Blood Transfusion Service, Tokyo Women's Medical College, \\ Tokyo 162, Japan
}

\begin{abstract}
Summary HLA-DRw9 antigen, of which frequency is relatively high in Japanese, is identified and analyzed by two-dimensional gel electrophoresis using anti-DRw9 alloantisera and monoclonal antibodies against human class II antigens. The DRw9 antigen consists of one set of heavy and light chains on the cell surface and the Ii chain is associated with the heavy chain-light chain complex in intracellular regions. The DRw9 light chain is distinct from the DR4 and DR7 light chains but the DRw9 heavy chain is identical with the DR4 and DR7 heavy chain, suggesting that the DRw9 light chain carries the antigenic specificity recognized by the anti-DRw9 alloantisera. The amount of the DRw9 antigen is extremely large compared with the other class II antigens in the total class II antigen pool, as reported previously for the DR4 antigen. The data presented in this paper indicate that the DRw9 antigen is present as an independent DR molecule and has the polypeptide constitution characteristic of the DR antigen.
\end{abstract}

\section{INTRODUCTION}

The major histocompatibility complex (MHC) class II antigen plays important roles in a number of immune phenomena such as $\mathrm{T}$ cell-macrophage interaction (Geha et al., 1979). In human, the HLA-D/DR region present in the short arm of No. 6 chromosome codes for at least three kinds of class II antigens, the DR, DC and SB antigens (Hurley et al., 1983). In addition, it has been suggested that the MT3 antigen which is defined serologically as a DR supertypic specificity is distinct from the DR, DC and SB antigens and belongs to the fourth group of the human class II antigens (Suzuki et al., 1983; Tanigaki et al., 1983). In general, the DC and MT3 antigens are in linkage disequilibrium with the DR antigens (Tanigaki et al., 1983) and no re-

Received January 10, 1984

* To whom correspondence and reprint requests should be addressed. 
combinations between the DC and DR antigens and between the MT3 and DR antigens have been reported. On the other hand, the SB locus is separated two centimorgan from the DR locus (Shaw et al., 1981).

The DR antigen is most extensively analyzed human class II antigen and ten alloantigens (DR1-DRw10) have been characterized by the microcytotoxicity test (HLA Nomenclature Committee, 1980). Biochemical analyses have been revealed the structure of most of the DR antigens (DRI-DRw8) (Shackelford et al., 1980; Charron et al., 1980; De Kretser et al., 1982). The DR antigen consists of two noncovalently associated glycoproteins, approximately 34,000 dalton heavy (alpha) and 29,000 dalton light (beta) chains. The third chain, Ii (invariant) chain, is also associated with the DR heavy chain-light chain complex in intracellular regions (Owen et al., 1981). The polymorphism of the DR antigens resides on the light chain (Shackelford et al., 1980). However, the DRw9 antigen, which occurs with a relatively high frequency in Japanese and a very low frequency in Caucasians (Baur and Danilovs, 1981), has not been biochemically identified and characterized yet.

In this report, the DRw9 antigen is identified by two-dimensional (2-D) gel electrophoresis using alloantisera and compared with other DR antigens.

\section{MATERIALS AND METHODS}

Cell lines. Transformed human B lymphoid cell lines were used in this study. Their HLA phenotypes are given in Table 1. L-KT12, L-KT13 and L-Pitot were kindly gifted from Dr. N. Kashiwagi, Kitasato University, Sagamihara. KCCL1448 was a generous gift from Dr. K. Ohkouchi, Kyushu University, Fukuoka. The cells were maintained in RPMI1640 (Gibco Co., N.Y.) medium supplemented with 10\% heatinactivated fetal bovine serum in the atmosphere of $5 \% \mathrm{CO}_{2}$ and $95 \%$ air at $37^{\circ} \mathrm{C}$.

Antisera and monoclonal antibodies. Alloantiserum 070702 (anti-DR7) was purchased from Hoechst Japan Co., Tokyo. Alloantiserum 1993 (anti-DRw9) was a kind gift from Dr. E. Tokunaga, Japan Red Cross Central Blood Center, Tokyo. Alloantisera T1016 (anti-DRw9), T2758 (anti-DRw9) and T2297 (anti-DR4) were obtained from multiparous women in Blood Transfusion Survice, Tokyo Women's Medical

Tabie 1. Human B lymphoid cell lines.

\begin{tabular}{|c|c|c|c|c|c|}
\hline & \multicolumn{5}{|c|}{ HLA } \\
\hline & $-A$ & $-B$ & $-\mathrm{C}$ & $-\mathrm{D}$ & $-\mathrm{DR}$ \\
\hline L-KT12 & $\mathrm{w} 24 / \mathrm{w} 31$ & w35/w52 & $w 4 /-$ & DB5/DB5 & w9/w9 \\
\hline KCCL1448 & $2 / 11$ & w55/w62 & w1/w3 & N.T.* & 5/w9 \\
\hline L-KT13 & $w 24 / w 31$ & w51/7 & $-/-$ & $\mathrm{KT} 2 / \mathrm{KT} 2$ & $4 / 4$ \\
\hline L-Pitot* & $29 / 29$ & w44/w44 & $-1-$ & w7/w7 & $7 / 7$ \\
\hline
\end{tabular}

All cell lines were established by Epstein-Barr virus (EBV) transformation. * N.T., not tested. ** L-Pitot was obtained from the offspring of a consanguineous marriage. 
Table 2. Serological specificities of the alloantisera.

\begin{tabular}{llccccrr}
\hline Lot No. & Specificity & $+/+$ & $+/-$ & $-/+$ & $-/-$ & Total & R-value \\
\hline 1993 & DRw9 & 14 & 0 & 0 & 23 & 37 & 1.000 \\
T2758 & DRw9 & 60 & 1 & 2 & 55 & 118 & 0.949 \\
T1016 & DRw9 & 35 & 1 & 1 & 142 & 179 & 0.965 \\
T2297 & DR4 & 80 & 3 & 4 & 92 & 192 & 0.921 \\
070702 & DR7 & 4 & 0 & 0 & 15 & 19 & 1.000 \\
\hline
\end{tabular}

$+/+$, antigen positive and reaction positive; $+/-$, antigen positive and reaction negative; $-/+$, antigen negative and reaction positive; $-/-$, antigen negative and reaction negative. Alloantiserum of Lot No. 070702 was tested by Boehringwerke, Hoechst Co. All other alloantisera were tested by one of the authors (T.J.).

College, Tokyo. The specificities of these alloantisera are shown in Table 2. The monoclonal antibodies L243 (Lampson and Levy, 1980), OKIal (Reinhertz et al., 1979), and MAS053C (Brickell et al., 1981) and MAS054C were purchased from Becton Dickinson Co., Sunnyvale, California, Ortho Pharmaceutical Co., Raritan, New Jersey, and SERA-LAB Ltd., Sussex, England, respectively. These monoclonal antibodies recognize human class II antigen monomorphic determinants. Antihuman beta-2 microglobulin monoclonal antibody was purchased from Olac Ltd., Bichester.

Sample preparations and two-dimensional (2-D) gel electrophoresis. Preparation of the plasma membrane of the cell line KCCL1448 was carried out by the method of Molner and co-workers (1969) with minor modifications as described previously (Suzuki et al., 1983). The membrane fractions of the cell line L-KT12, L-KT13 and L-Pitot were prepared according to the method of Koyama and co-workers (1977). The membrane glycoproteins were purified from the plasma membrane and the membrane fractions by the Lentil-lectin affinity chromatography and labeled with ${ }^{125} \mathrm{I}$ by the chloramine $\mathrm{T}$ method (Koyama et al., 1977).

$\left.{ }^{[5} \mathrm{S}\right]$ Methionine-labeled cellular proteins were prepared by the method of Jones (1980).

Immunoprecipitation and 2-D gel electrophoresis were performed as described previously (Suzuki et al., 1983). 125I-Labeled proteins were detected by the autoradiography. ${ }^{35}$ S-Labeled proteins were visualized by the fluorography according to the method of Bonner and Laskey (1974). Unlabeled membrane glycoproteins were stained by Coomassie brilliant blue.

\section{RESULTS}

Identification of the DRw9 antigen

To identify the DRw9 antigen, ${ }^{125}$ I-labeled membrane glycoproteins from the $D R w 9$-homozygous cell line L-KT12 and the DRw9-positive cell line KCCL1448 were 
precipitated with the monoclonal antibodies, anti-DRw9 alloantisera or normal human serum and the resulting immunoprecipitate was analyzed by $2-\mathrm{D}$ gel electrophoresis (Fig. 1). The monoclonal antibody L243 precipitates one set of heavy and light chains of the class II antigen from the cell line L-KT12 (Fig. 1A). The microheterogeneity in the light chain is considered to be attributable to both the variability in the sialic acid content and the difference in the oligosaccharide type (Shackelford et al., 1981). Other three monocional antibodies (OKIal, MAS053C and MAS054C) also precipitated the same set of the heavy and light chains from the cell line L-KT12. The anti-DRw9 alloantiserum T1016 precipitates the same set of the heavy and light chains (Fig. 1B). Only the same set of the heavy and light chains are also precipitated from the other DRw9-positive cell line KCCL1448 with the anti-DRw9 alloantiserum T1016 (Fig. 1C). The other anti-DRw9 alloantiserum (1993) precipitated the same set of the heavy and light chains from both the cell lines L-KT12 and KCCL1448, as well. However, normal human serum do not precipitate any class II antigens (Fig. 1D). The anti-DRw9 alloantisera specific light chain was not precipitated from the DRw9-negative cell lines (data not shown). Furthermore, the electrophoretic mobility of the DRw9 alloantisera specific light chain was distinct from that of the MT3 light chain of these cell lines (Yabe et al, submitted), as in the case of the light chains of DR4 and MT3 antigens in a DR4-homozygous cell line (Suzuki et al., 1983). It was also observed that both the heavy and light chains of the DRw9 alloantisera specific antigen differ from those of the DC-like (TB21) antigen in the cell line L-KT12 (Yabe et al., submitted). Therefore, these anti-DRw9 alloantisera specific heavy and light chains are considered to be the components of the DRw 9 antigen.

\section{Comparison of the $D R w 9$ antigen with the $D R 4$ and $D R 7$ antigens}

We have identified the DR4 and DR7 antigens on 2-D gel using alloantisera (Suzuki et al., 1983, Yabe et al., submitted). To clarify the difference in polypeptides between the DRw9 and the other DR antigens, the DRw9 antigen is compared with the DR4 and DR7 antigens from the cell lines L-KT13 and L-Pitot, respectively, by 2-D gel electrophoresis (Fig. 2). The positions of the light chains on the 2-D gel are different from one another among the DR4, DR7 and DRw9 antigens: The pI of the DRw9 light chain is most basic and that of the DR4 light chain from the cell line LKT13 is most acidic. On the other hand, no differences in the molecular weight and pI of the heavy chains are observed among the DR4, DR7 and DRw9 antigens.

\section{Relative amount of DRw9 antigen in the total class II antigen pool}

In order to examine the relative amount of the DRw9 antigen in the total class II antigen pool, the membrane glycoproteins from the cell line L-KT12 were subjected to 2-D gel electrophoresis and detected by Coomassie brilliant blue staining (Fig. 3). The DRw9 antigen was identified by the anti-DRw9 alloantisera. The other class II and class $I$ antigens were identified by the anti-human class II antigen monoclonal antibodies and anti-human beta- 2 microglobulin monoclonal antibody, respectively. The data indicate that the amount of the DRw9 antigen is extremely large compared 


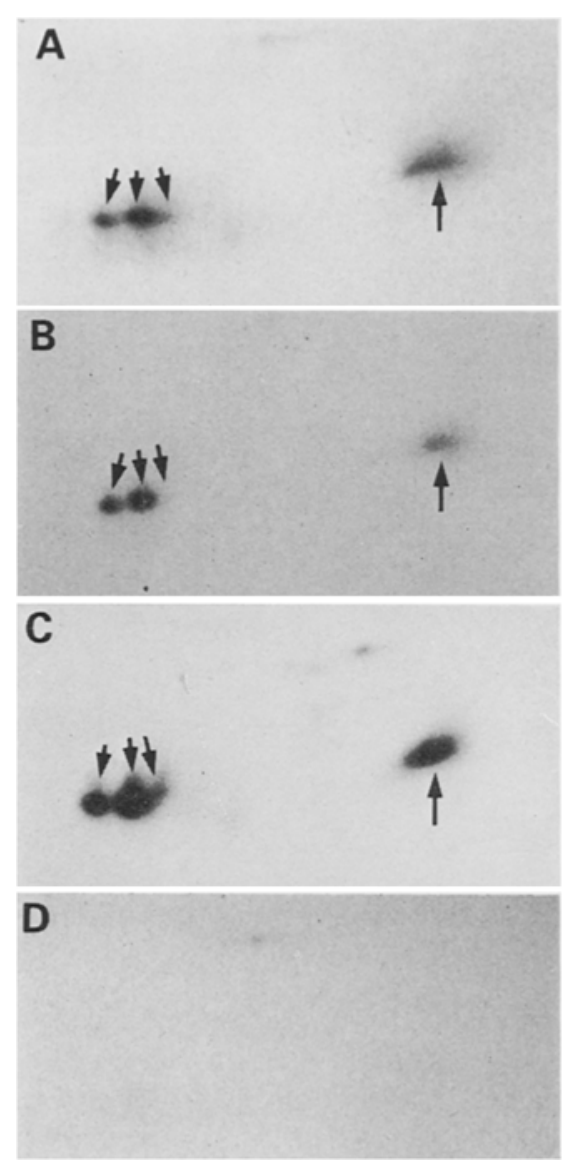

Fig. 1

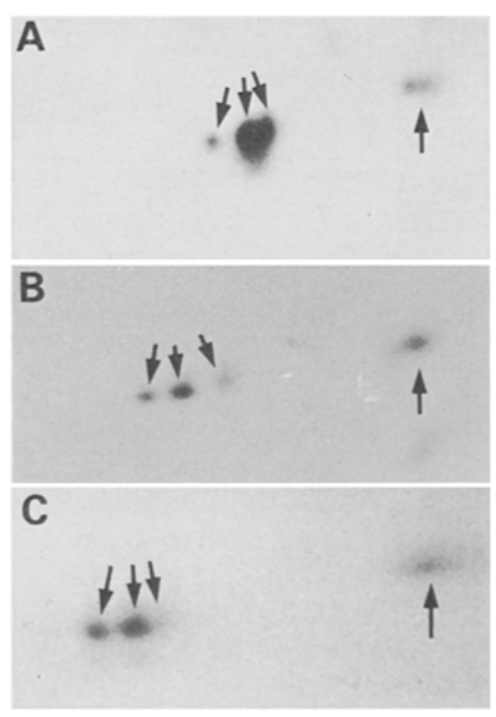

Fig. 2

Fig. 1. 2-D gel analysis of the DRw9 antigen from the ${ }^{125}$ I-labeled membrane glycoproteins. A, the immunoprecipitate from the L-KT12 cell with the anti-human class II antigen monoclonal antibody L243; B, the immunoprecipitate from the L-KT12 cell with anti-DRw9 alloantiserum T1016; $\mathrm{C}$, the immunoprecipitate from the plasma membrane glycoproteins of KCCL1448 cell with anti-DR w9 alloantiserum T1016; D, the immunoprecipitate from the L-KT12 cell with normal human serum as control. The basic end of the NEPHGE gel is on the left and the direction of SDS-PAGE is from top to bottom. The heavy and light chains of the DRw9 antigen are indicated by upward and downward arrows, respectively.

Fig. 2. Comparison of the DRw9 antigen with the DR4 and DR7 antigens. A, the immunoprecipitate from the L-KT13 cell with anti-DR4 alloantiserum T2297; $\mathrm{B}$, the immunoprecipitate from the L-Pitot cell with anti-DR7 alloantiserum 070702; C, the immunoprecipitate from the L-KT12 cell with anti-DRw9 alloantiserun 1993. Gel orientation is the same as in Fig. 1. The heavy and light chains of DR antigens are indicated by upward and downward arrows, respectively. 


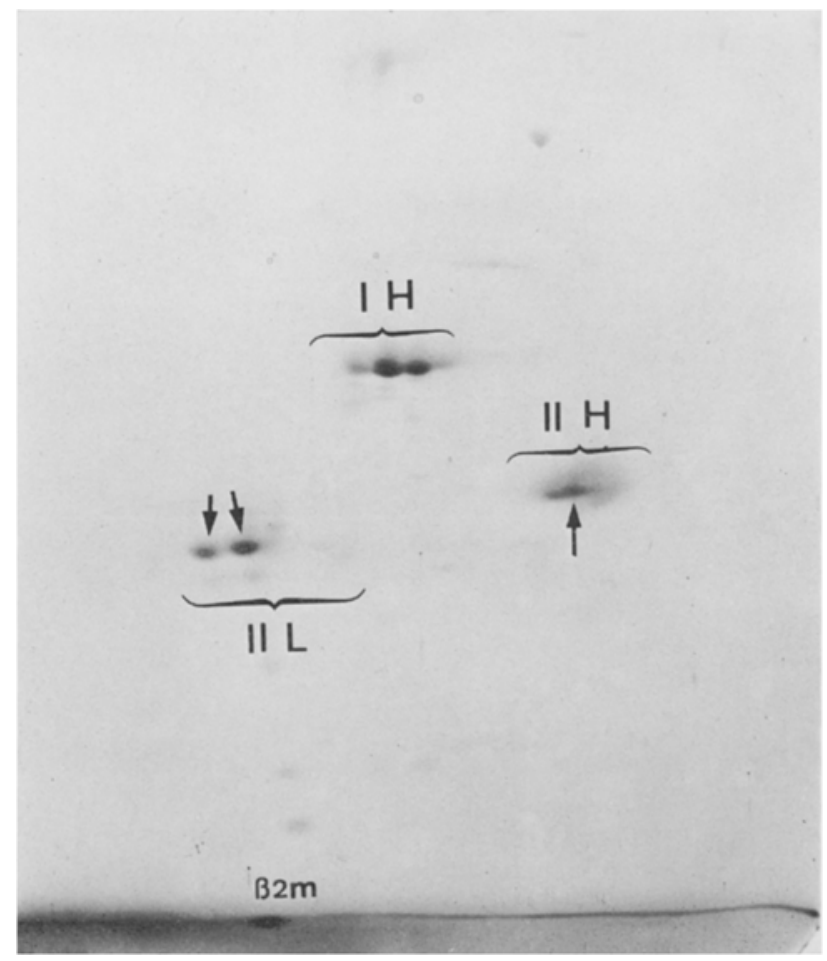

Fig. 3. 2-D gel analysis of the DRw9 antigen in unlabeled membrane glycoproteins from the cell line L-KT12. The heavy and light chains of the DRw9 antigen are indicated by upward and downward arrows, respectively. I H, class I heavy chains; II $\mathrm{H}$, class II heavy chains; II L, class II light chains; $\beta_{2} \mathrm{~m}$, beta-2 microglobulin.

with the other class II antigens of this cell line.

\section{Association of the Ii chain in intracellular regions}

To reveal the polypeptide constitution of the DRw9 antigen in intracellular regions, [35] ${ }^{35}$ methionine-labeled L-KT12 cell proteins were precipitated with anti-DRw9 alloantiserum T2758 or normal human serum and the resulting immunoprecipitate was analyzed by 2-D gel electrophoresis (Fig. 4). The anti-DRw9 alloantiserum T2758 precipitates the heavy and light chains of the DRw9 antigen together with the li chain (Fig. 4A) but normal human serum does not precipitate any class II antigens (Fig. 4B). The same result was obtained by the use of the other DRw9-positive cell line KCCL1448. These results indicate that the DRw9 antigen associates with the Ii chain in intracellular regions. 


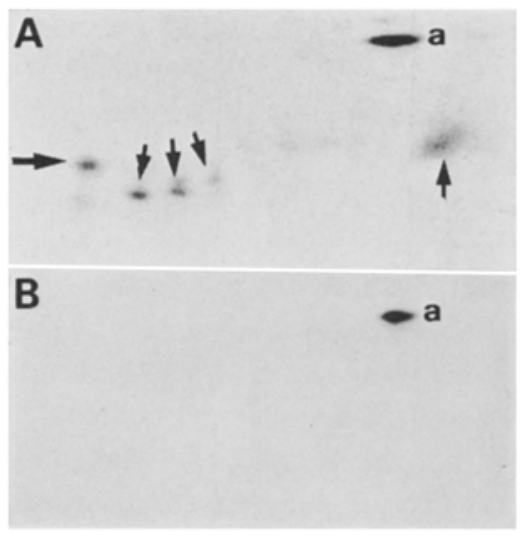

Fig. 4. 2-D gel analysis of the DRw9 antigen in ${ }^{35} \mathrm{~S}$-labeled cell proteins from the cell line L-KT12. A, the immunoprecipitate with anti-DRw9 alloantiserum T2758; $\mathbf{B}$, the immunoprecipitate with normal human serum. The heavy and light chains of the DRw9 antigen are indicated by upward and downward arrows, respectively. The Ii chain is shown by a horizontal arrow. a, actin.

\section{DISCUSSION}

The DRw9 antigen which is defined by the microcytotoxicity test was recognized at the Eighth International Workshop on Histocompatibility Testing 1980 (Terasaki et al., 1981). The frequency of the DRw9 antigen is relatively high in Japanese: The phenotype frequencies are 0.230 in Japanese, 0.024 in Caucasian and 0.053 in Negro (Colombe and Payne, 1981). In this study, the DRw9 antigen has been biochemically identified for the first time, using 2-D gel electrophoresis and anti-DRw9 alloantisera. The anti-DRw9 alloantisera specific heavy and light chains shown in this paper are considered to be the components of the DRw9 antigen for the following reasons: 1) Since all the monoclonal antibodies against human class II antigen used precipitate the anti-DRw9 alloantisera specific heavy and light chains, these heavy and light chains are the components of the human class II antigens. 2) All the anti-DRw9 alloantisera used precipitate only these heavy and light chains. 3) The anti-DRw9 alloantisera specific heavy and light chains are precipitated from the DRw9-positive cells (L-KT12 and KCCL1448) but not from the DRw9-negative cells. 4) The electrophoretic mobility of the anti-DRw9 alloantisera specific heavy chain is identical with that of the other DR heavy chains, as is generally observed in the DR antigens. 5) The antiDRw9 alloantisera specific light chain is identical in the DRw9 positive cell lines but different from the other types of the DR light chains. 6) The anti-DRw9 alloantisera specific light chains distinct from the light chains of the MT3 and DC-like antigens in a cell line. 7) Normal human serum does not precipitate these heavy and light chains. Furthermore, these data suggest that the DRw9 light chain carries the antigenic specificity recognized by the anti-DRw9 alloantisera. 
The amount of the DRw9 antigen is extremely large compared with the other class II antigens in the total class II antigen pool of the cell line L-KT12 (Fig. 3). It has been observed in all the B lymphoid cell lines examined, including KCCL1448, L-KT13 and L-Pitot, that most of the class II antigen consists of the DR antigen (Suzuki et al., 1983, Yabe et al., submitted). These results suggest that the DRw9 antigen and the other DR antigens play important roles in the immune response.

It has been reported that the DR antigen consist of the heavy and light chains on the cell surface and that the Ii chain is associated with the heavy chain-light chain complex in intracellular regions (Owen et al., 1981). The data presented in this paper also indicate that the DRw9 antigen consists of the heavy and light chains on the cell surface (Figs. 1 and 3) and that the Ii chain is associated with the DRw9 antigen in intracellular regions (Fig. 4). The findings in this study show that the DRw9 antigen has the polypeptide constitution characteristic of the DR antigen.

Among the ten recognized DR antigens, the gene frequency of the DRw9 antigen is the third highest $(0.122)$ in Japanese (Baur and Danilovs, 1981). Since the existence of the DRw9 antigen as an independent DR molecule has been proved biochemically by this study, the DRw9 antigen will become a useful genetic marker in the D/DR region in Japanese.

Acknowledgements This study was supported by a Grant-in-Aid for Scientific Research from the Ministry of Education, Science and Culture, and a Research Grant for Intractable diseases from the Ministry of Health and Welfare, Japan. We wish to thank Dr. I. Kondo, Dr. A. Noguchi, Miss Y. Yamanouchi, Miss K. Yamakawa, and Miss M. Onuki, Basic Medical Sciences, University of Tsukuba, for helpful suggestions and technical assistance.

\section{REFERENCES}

Baur, M.P., and Danilovs, J.A. 1981. Population analysis of HLA-A, B, C, DR, and other genetic markers. In Histocompatibility Testing 1980, Terasaki, P.J., ed., UCLA Press, Los Angeles, pp. 955-993.

Bonner, W.M., and Laskey, R.A. 1974. A film detection method for tritium-labeled proteins and nucleic acids in polyacrylamide gels. Eur. J. Biochem. 46: 83-88.

BrickelI, P.M., McConnell, I., Milstein, C., and Wright, B. 1981. A monoclonal antibody to the HLA-DR product recognizes a polymorphic Ia determinant in mice. Immunology 43: 493-501.

Colombe, B., and Payne, R. 1981. 8th Workshop Joint Reports 8 w12 (DRw3+10). In Histocompatibility Testing 1980, Terasaki, P.J., ed., UCLA Press, Los Angeles, pp. 543-545.

Charron, D.J., and McDevitt, H.O. 1980. Characterization of HLA-D-region antigens by two-dimensional gel electrophoresis. Molecular genotyping. J. Exp. Med. 152: 18s-36s.

De Kretser, T.A., Crumpton, M.J., Bodmer, J.G., and Bodmer, W.F. 1982. Demonstration of two distinct light chains in HLA-DR-associated antigens by two-dimensional gel electrophoresis. Eur. J. Immunol. 12: 214-221.

Geha, R.S., Milgrom, H., Broff, M., Aipert, S., Martin, S., and Yunis, E.J. 1979. Effect of antiHLA antisera on macrophage-T cell interaction. Proc. Natl. Acad. Sci. U.S.A. 76: 4038-4041.

HLA Nomenclature Committee. 1980. Nomenclature for factors of the HLA system, 1980. Tissue antigen 16: 113-117.

Hurley, C.K., Geiles, R.C., and Capra, J.D. 1983. The human MHC: evidence for multiple HLAD-region genes. Immunol. Today 4: 219-226. 
Jones, P.P. 1980. Analysis of radiolabeled lymphocyte proteins by one- and two-dimensional polyacrylamide gel electrophoresis. In Selected Methods in Cellular Immunology, Shigi, S.M., ed., W.H. Freeman and Company, San Francisco, pp. 398-440.

Koyama, K., Nakamuro, K., Tanigaki, N., and Pressman, D. 1977. Alloantigens of human lymphoid cell lines; 'Human Ia-like antigens': Alloantigenic activity and cell line, organ and tissue distribution as determined by radioimmunoassay. Immunology 33: 217-230.

Lampson, L.A., and Levy R. 1980. Two populations of Ia-like molecules on a human B cell line. J. Immunol. 125: 292-299.

Molner, J., Markovic, G., Chao, H., and Molnar, Z. 1969. Glycoproteins of Ehrlich ascites carcinoma cells: Separation of plasma and endoplasmic reticular membrane fractions. Arch. Biochem. Biophys. 134: 524-532.

Owen, M., Kissonerghis, A.M., Lodish, H.F., and Crumpton, M.J. 1981. Biosynthesis and maturation of HLA-DR antigens in vivo. J. Biol. Chem. 256: 8987-8993.

Reinhertz, E.L., Kung, P.C., Pesando, J.M., Ritz, J., Goldstein, G., and Schlossman, S.F. 1979. Ia determinants on human T-cell subsets defined by monoclonal antibody. J. Exp. Med. 150: 14721482.

Shackelford, D.A., and Strominger J.L. 1980. Demonstration of structural polymorphism among HLA-DR light chains by two-dimensional gel electrophoresis. J. Exp. Med. 150: 1472-1482.

Shackelford, D.A., Lampson, L.A., and Strominger, J.L. 1981. Analysis of HLA-DR antigens by using monoclonal antibodies: recognition of conformational differences in biosynthetic intermediates. J. Immunol. 127: 1403-1410.

Shaw, S., Kavathas, P., Pollack, M.S., Charmot, D., and Mawas, C. 1981. Family studies define a new histocompatibility locus, SB, between HLA-DR and GLO. Nature 293: 745-747.

Suzuki, M., Maeda, H., Mukai, R., Yabe, T., and Hamaguchi, H. 1983. Identification of the MT3 molecule using two-dimensional gel electrophoresis and alloantisera. Immunogenetics 18: 575583.

Tanigaki, N., Tosi, R., Duquesnoy, R.J., and Ferrara, G.B. 1983. Three Ia species with different structures and alloantigenic determinants in a HLA-homozygous cell line. J. Exp. Med. 157: 231-247.

Terasaki, P.I., Park, M.S., Bernoco, D., Opelz, G., and Mickey, M.R. 1981. Overview of the 1980 International Histocompatibility Workshop. In Histocompatibility Testing 1980, Terasaki, P.J., ed., UCLA Press, Los Angeles, pp. 1-17.

Yabe, T., Suzuki, M., Satake, M., Juji, T., and Hamaguchi, H. The MT3 specificity is located on a novel human class II antigen distinct from the HLA-DR and DC-like antigens. (submitted) 